\title{
Multiple Sclerosis in Hokkaido, the Northernmost Island of Japan: Prospective Analyses of Clinical Features
}

\author{
Toshiyuki Fukazawa*,**, Kunio Tashiro*, Takeshi Hamada**, Fumio MoriwaKA*, \\ Akihisa Matsumoto***, Kohji Shima*** and Yasunori Maruo****
}

\begin{abstract}
We analyzed the clinical features of multiple sclerosis (MS) prospectively seen between July 1986 and October 1989 on Hokkaido island, the northernmost part of Japan. Clinical features were generally considered to be intermediate between the previous Japanese reports and those of Western countries. Devic's disease was rare and simultaneous bilateral visual loss at on set was not too common this series, differing from that previously reported of Japanese MS. The high incidence of acute transverse myelopathy and lesser involvement of the cerebellum, however, support the previous view. Further clinical and epidemiological studies will be necessary on this island.
\end{abstract}

(Internal Medicine 31: 349-352, 1992)

Key words: Devic's disease, epidemiology, genetic background, acute transverse myelopathy, optic neuritis

\section{Introduction}

It is thought that there are fewer cases of multiple sclerosis (MS) in Japan than in Western countries, and previous studies have emphasized some distinct clinical features of Japanese MS (1-4). Prevalence studies in Western Europe (5), North America (6) and Southern hemisphere $(7,8)$ have shown an increasing frequency of MS with increasing latitude. Hokkaido island is the northernmost part of Japan, being almost in the same latitude as Minnesota, U.S.A., where a higher incidence of MS is wellknown. However, precise epidemiological and clinical data from this island have not yet been reported. Here, the clinical features of MS in Hokkaido island were analyzed prospectively between July 1986 and October 1989, based on our research charts. The data forms were filled out by one neurologist who examined the patients more than once during the follow-up period.

\section{Geography and Background}

Hokkaido, the second largest island and northernmost part of Japan, is located between 42 and 46 degrees northern latitude, with an area of $83,500 \mathrm{~km}^{2}$ and a population of about 5.7 million (1989). The people have ancestors from various parts of Japan, since Hokkaido was first reclaimed about 120 years ago, and cultivaters came from different parts of Japan. The native inhabitants of Hokkaido are said to be the Ainu tribe, but it remains a controversial issue as to where their ancestors migrated from. Their population rapidly declined after the influx of recultivaters.

Hokkaido might be considered separate from the rest of Japan in a zoological sense. Blakiston (8) noted that many species of birds which inhabit Hokkaido, do not inhabit the main islands; referring also to a similar division in mammalia; for example, brown bears subsist only in Hokkaido. His proposal of a zoological line of demarcation, which was later called "Blakiston's line", is famous and is described in textbooks of primary schools.

\section{Material and Methods}

The research charts for each MS patient were used to record and compile the details of clinical and demographic features. HLA typing results, family history, CSF analysis, abnormalities on evoked responses and neuroimagings (brain CT, brain and spinal cord MRI)

From *the Department of Neurology, Hokkaido University Hospital, Sapporo, ${ }^{* *}$ Hokuyukai Neurological Hospital, Sapporo, *** Department of Neurology, National Sapporo Minami Hospital. Sapporo and ***** Department of Neurology, Hakodate City Hospital, Hakodate Received for publication September 19, 1990; Accepted for publication October 14, 1991

Reprint requests should be addressed to Toshiyuki Fukazawa, M.D., Hokuyukai Neurological Hospital, 2-2-4-30 Niju Yon-Ken, Nishi$\mathrm{Ku}$, Sapporo 060, Japan 
were also recorded when available. All patients had hematologic and biochemical profiles, collagen screening, serologic tests for syphilis and HTLV-1 antibody. Behçet's disease, which is relatively frequent in Hokkaido, was carefully excluded.

The authors performed thorough neurological evaluations for patients with a diagnosis of MS, including probable or possible cases according to some diagnostic criteria, and all data forms were filled out by one author for all consecutive 97 patients. The history and previous symptoms were re-assessed from patients, family members, or both. Medical records of previously referred hospitals were also reviewed when available. Among 97 patients, the patients follwed more than 1 year who were clinically definite or laboratory supported definite MS cases as determined according to the criteria of Poser et al (9) were selected for the analyses. One case of Devic's disease was exculded because it did not meet the criteria. Finally, a total of 62 patients met the criteria and were used as subjects for the analyses. Of these 62 patients, 61 were clinically definite and 40 were laboratory supported definite MS.

\section{Results}

Five patients were born outside Hokkaido, but four had spent their childhood and adolescence in Hokkaido. Thirty-six patients were living in Sapporo, while the others were distributed in different parts of Hokkaido. The men to women ratio was 1 to 1.95 . The mean age at onset was 30 years for men, 32 for women and 31 for the over all series. The mean duration of illness was 14 years (range, 1 to 44 ). Two patients $(3 \%)$ were reported to have a family member with monophasic optic neuritis, one patient $(2 \%)$ had a family member with probable MS and one patient $(2 \%)$ had a family member with definite MS.

Initial neurological symptoms are shown in Table 1 . The most common symptoms were motor weakness in 23 patients $(37 \%)$, followed by numbness or paresthesia in 20 patients $(32 \%)$ and visual loss in 17 patients $(27 \%)$.

Table 1. Initial Neurological Symptoms

\begin{tabular}{lc}
\hline Visual loss & $17(27 \%)$ \\
$\quad$ one eye & $13(21 \%)$ \\
both eyes & $4(6 \%)$ \\
Numbness, paresthesia & $20(32 \%)$ \\
Pain & $1(2 \%)$ \\
Trigeminal neuralgia & $1(2 \%)$ \\
Motor weakness & $23(37 \%)$ \\
Double vision & $7(11 \%)$ \\
Facial palsy & $3(5 \%)$ \\
Vertigo & $1(2 \%)$ \\
Speech disturbance & $3(5 \%)$ \\
Bladder dysfunction & $5(8 \%)$ \\
Imbalance & $7(11 \%)$ \\
\hline
\end{tabular}

The neurological signs and symptoms during the course of illness are shown in Table 2. The sites of lesions as evident clinically were; optic in 45 patients $(73 \%)$, spinal in 53 patients $(85 \%)$, brainstem in 42 patients $(68 \%)$, cerebellum in 32 patients $(52 \%)$ and cerebrum in 20 patients $(32 \%)$.

Clinical forms are shown in Table 3, compared with previously reported study (3). Forty-three patients (69\%) had a clinical course of remissions and relapses (R-R), 17 patients $(28 \%)$ transmitted to progressive course from R-R course, 2 patients ( $3 \%$ ) had a generally progressive course from onset with some acute fluctuations.

Motor disability at the last examination was graded after the method of Shibasaki et al (3): normal in 18 $(29 \%)$, slight in $16(26 \%)$, moderate in $13(21 \%)$, severe in $11(18 \%)$ and bedridden in 4 patients $(6 \%)$. Visual acuity could be tested in 58 patients. For the right eye at the last examination, 2 patients $(3 \%)$ had complete visual loss, 7 patients $(12 \%)$ less than $20 / 200$, and the

Table 2 Neurological Signs and Symptoms during the Course of Illness

\begin{tabular}{|c|c|}
\hline Convulsion & $4(6 \%)$ \\
\hline Visual loss & $37(60 \%)$ \\
\hline one eye & $18(29 \%)$ \\
\hline both eyes & $21(34 \%)$ \\
\hline Optic atrophy & $45(73 \%)$ \\
\hline one eye & $18(29 \%)$ \\
\hline both eyes & $27(44 \%)$ \\
\hline Double vision & $30(48 \%)$ \\
\hline Ocular palsy & $14(23 \%)$ \\
\hline Internuclear opthalmoplegia & $14(23 \%)$ \\
\hline unilateral & $6(10 \%)$ \\
\hline bilateral & $8(13 \%)$ \\
\hline Nystagmus & $23(37 \%)$ \\
\hline Dysarthria & $22(35 \%)$ \\
\hline Dysphagia & $7(11 \%)$ \\
\hline Facial palsy (peripheral) & $19(31 \%)$ \\
\hline Motor weakness & $51(82 \%)$ \\
\hline paraparesis & $24(39 \%)$ \\
\hline tetraparesis & $10(16 \%)$ \\
\hline hemiparesis & $20(32 \%)$ \\
\hline monoparesis & $13(21 \%)$ \\
\hline Increased deep tendon reflex & $41(66 \%)$ \\
\hline Babinski's sign & $51(82 \%)$ \\
\hline Ataxia & $31(50 \%)$ \\
\hline Sensory signs & $49(79 \%)$ \\
\hline face & $3(5 \%)$ \\
\hline spinal level & $31(50 \%)$ \\
\hline segmental sensory loss & $6(10 \%)$ \\
\hline hemisensory loss & $7(11 \%)$ \\
\hline Lhermitte's sign & $11(18 \%)$ \\
\hline Pain & $26(42 \%)$ \\
\hline Sphincter disturbance & $34(55 \%)$ \\
\hline Uhthoff's phenomenon & $8(13 \%)$ \\
\hline Girdle sensation & $15(24 \%)$ \\
\hline Painful tonic spasm & $12(20 \%)$ \\
\hline Acute transverse myelopathy & $17(27 \%)$ \\
\hline recurrent & $7(11 \%)$ \\
\hline non-recurrent & $10(16 \%)$ \\
\hline
\end{tabular}


Table 3. Clinical Froms (\% of patients)

\begin{tabular}{lccc}
\hline & $\begin{array}{c}\text { Hokkaido } \\
(1989) \\
(62)^{*}\end{array}$ & $\begin{array}{c}\text { Kyushu Univ. } \\
(1981) \\
(60)\end{array}$ & $\begin{array}{c}\text { Maida Vale } \\
(1981) \\
(204)\end{array}$ \\
\hline Multiple & 32 & 27 & 43 \\
Optic-spinal & 15 & 13 & 6 \\
Optic-spinal-brainstem & 13 & 22 & 9 \\
Spinal-brainstem-cerebellar & 8 & 2 & 3 \\
Optic-spinal-cerebellar & 6 & 2 & 9 \\
Spinal-brainstem & 5 & 0 & 2 \\
Optic-brainstem & 3 & 5 & 6 \\
Optic-brainstem-cerebellar & 2 & 2 & 4 \\
Optic-cerebllar & 0 & 2 & 0 \\
Others & 16 & 28 & 15 \\
Total & 100 & 100 & 100 \\
\hline
\end{tabular}

* Number in parentheses indicate number of patients

remaining 49 patients $(85 \%)$ better than $20 / 200$. For the left eye, 3 patients $(5 \%)$ had complete visual loss, 5 patients $(9 \%)$ less than $20 / 200$, the other 50 patients $(86 \%)$ better than $20 / 200$.

Brain MRI was done in 59 patients; 43 patients (73\%) showed a definite abnormal high-intensity area in the white matter, mainly in the periventricular region of the cerebral hemisphere.

Brainstem auditory evoked potentials (BAEP) was done in 27 patients; 15 patients $(56 \%)$ were abnormal with unilateral or bilateral loss of $\mathrm{V}$ waves or a decrease in the amplitude of this wave. Pattern reversal visual evoked potentials (VEP) was done in 25 patients; 20 patients $(80 \%)$ were abnormal with prolongation of the P100.

CSF was tested in 56 patients; pleocytosis (12 to $222 \mathrm{cells} / \mathrm{mm}^{3}$ ) was found in 24 patients $(43 \%)$ and raised protein $(61$ to $100 \mathrm{mg} / \mathrm{dl})$ in 3 patients $(5 \%)$. CSF IgG was estimated in 47 patients and IgG index was abnormal with a value of more than 0.66 in $10(21 \%)$. An oligoclonal pattern of CSF IgG on agarose electrophoresis was found $31(70 \%)$ of of the 47 patients tested.

\section{Discussion}

Numerous studies on MS in Japan have shown the low prevalence and the difference of clinical features as compared with those in Western countries $(3,10-12)$. However, only a few recent clinical studies of Japanese MS have been reported despite marked changes in life style and medical environment. A nationwide survey on the clinical features of MS in Japan was done in 1972 (1) and 1982 (2). One precise study was reported from the southern part of Japan (3), but no such study was reported in Hokkaido despite its unique geographical and biological characteristics. In the present study of MS in Hokkaido, the research charts were all filled out by the same neurologist to minimize assessment bias.

The diagnosis of MS is sometimes difficult because other diseases, such as collagen vascular disease, neurosyphilis and neuro-Behçet's disease may have similar clinical features; these were excluded from the present study by clinical, paraclinical and laboratory examinations. Since patients with HTLV-1 antibody may show clinical features similar to MS (13), these patients were also excluded from this study.

Clinical symptomatology and sites of lesion were somewhat different from the previous Japanese reports. Simultaneous bilateral visual loss at onset was not that common; visual disability was not so severe. Devic's disease shows acute bilateral visual loss and acute transverse myelitis occurring successively, and is considered a type of multiple sclerosis. The high frequency of Devic's disease had been said to be one of the characteristic features of Japanese MS $(11,12,14)$. There was only one case of Devic's disease among 97 cases suspected of MS in our series, and it was excluded in this study because it did not meet the criteria of definite MS. Early reports pointed out a high incidence of Devic's disease, accounting for $64.8 \%$ of 270 cases of demyelinating disease in Japan $(11,14)$. The incidence of Devic's disease, however, gradually diminished to $28.3 \%$ of 328 cases during $1956-1965(12)$, then $7.6 \%$ of 1,084 cases in 1972 (1) and finally to only $1.5 \%$ of 137 cases in 1975 (15). Satoyoshi et al (15) commented that this remarkable decline of Devic's disease was due to changes in the diagnostic criteria of MS and Devic's disease, and the long-term follow-up study. A recent study from the southern part of Japan showed only two cases of Devic's disease among 60 cases with clinically definite MS (3). It can be concluded that Devic's disease is not common even in Japan.

Forty-four percent of patients in a Japan nationwide survey (1) on MS had simultaneous bilateral visual loss as an initial symptom; this was $22 \%$ in the recent Kyushu series (3), and only 4 patients (6\%) in the present series. This is one of the important features of this study compared with generally accepted reports who state that simultaneous bilateral visual loss is more common in Japanese MS. Only a few previous reports $(15,16)$ showed that there is little difference between Japanese MS and the reported Western MS cases. Interestingly, the present study reconfirms the same characteristic aspects as in previous Japanese reports: high frequency of acute transverse myelopathy and less common involvement of cerebellum. The optic-spinal form, based on a combination of the clinically determined sites of lesions was found in $15 \%$ of patients in the present series, $12 \%$ in the Kyushu series (3), 33\% in the Oriental group of the Hawaian series (17), 36\% in Taiwan's series (18), $63.3 \%$ in Malaysian's series (19), and only $6 \%$ in the British series (3). This may indicate that genetic factors play a major role in presenting different clinical features. 
However, most previous studies have been based on a retrospective comparison of clinical data from the medical records. A prospective cooperative study should be done under the same diagnostic criteria and the same methods of assessment of the clinical features.

Brain MRI abnormality in the present series was $73 \%$, although $87-100 \%$ of clinically definite MS patients had abnormal MRI in Western series $(20-22)$. This difference may reflect the difference of clinical forms; among 16 patients who had normal MRI in the present series, 7 were the optic-spinal form. Abnormalities in the evoked potentials were seen in $56 \%$ for BAEP and $80 \%$ for VEP, being compatible with other series (23). Only $21 \%$ of patients showed an abnormally increased IgG index in the CSFs of the present series, compared with $58-90 \%$ in other series $(24,25)$. A low frequency of abnormalities of IgG ratios or IgG index were demonstrated in previous Japanese reports $(26,27)$.

This is the first precise data to evaluate the clinical features of MS on Hokkaido island, the northernmost part of Japan. The historical and geographical aspects of this island are entirely different from the rest of Japan. A difference in the clinical features of MS between Hokkaido and the southern part of Japan seem to be present. It will be necessary to confirm to collect and analyze all MS cases in Hokkaido to confirm this preliminary report.

Acknowledgments: We are grateful to Dr. H. Sasaki, Dr, T. Matsuura, Dr. T. Yanagihara, Dr. K. Hamada and Mr. S.Dei (msw) for help in evaluating patients, and Mr. K. Sugiyama and Mr. R. Takano for help in laboratory testings.

\section{References}

1) Kuroiwa $Y$, Igata A, Itahare K, et al. Nationwide survey of multiple sclerosis in Japan. Clinical analysis of 1,084 cases. Neurology 25: 845, 1975.

2) Shibasaki H, Igata A, Maeda K. Nationwide survey of multiple sclerosis in Japan. in: Annual Report of the Research Committee of Neuroimmunological Diseases of the Ministry of Health and Welfare of Japan, Igata A, Ed. Nakanishi Press, Tokyo, 1983, p.17.

3) Shibasaki H, McDonald WI, Kuroiwa Y. Racial modification of clinical picture of multiple sclerosis: Comparison between British and Japanese patients. J Neurol Sci 49: 253, 1981.

4) Kuroiwa Y, Shibasaki H, Ikeda M. Prevalence rate and its northto-south gradient of multiple sclerosis in Japan. in: Multiple Sclerosis East and West, Kuroiwa Y, Kurland LT, Eds. Kyushu University Press, Kyushu, 1982, p.43.

5) Kurtzke JF. Geographic distribution of multiple sclerosis: An update with special reference to Europe and Mediterenian region. Acta Neurol Scand 62: 65, 1980.

6) Kurtzke JF, Beebe GW, Norman JE Jr. Epidemiology of multiple sclerosis in U.S. veterans: 1.Race, sex, and geographic distribution.
Neurology 29: 1228, 1979.

7) Hammond SR, McLeod JG, Millingen KS, et al. The epidemiology of multiple sclerosis in three Australian cities: Perth, Newcastle and Hobart. Brain 111: 1, 1988.

8) Blakiston TW. Japan in Yezo, with itineraries of distances on travelled routes, and a sketch map of Yezo. Yokohama: Japan Gazette Office, 38, 1883.

9) Poser CM, Paty DW. Scheinberg L, et al. New diagnostic criteria for multiple sclerosis: Guidelines for research protocols. Ann Neurol 13: 227, 1983.

10) Kuroiwa Y, Shibasaki H. Clinical studies of multiple sclerosis in Japan. 1. A current appraisal of 83 cases. Neurology (Minneapolis) 23: 609, 1973.

11) Okinaka $S$, Tsubaki $T$, Kuroiwa $Y$, Toyokura $Y$, Imamura $Y$, Yoshikawa M. Multiple sclerosis and allied disease in Japan: Clinical characteristics. Neurology (Minneap) 8: 756, 1958.

12) Tsubaki T. Clinical findings and diagnosis of multiple sclerosis: An actual figure in Japan. Clin Neurol (Tokyo) 6: 675, 1966.

13) Tashiro $K$, Maruo $Y$, Shiokawa $T$, et al. MS-like features in patients with HTLV-1 associated myelopathy. in: HTLV-1 and the Nervous System, Osame M, Ed. Alan R Liss, Inc, NY, 1989, p.385.

14) Okinaka $S$, McAlpine $D$, Miyagawa $K$, et al. Multiple sclerosis in northern and southern Japan. Word Neurol 1: 22, 1960.

15) Satoyoshi E, Saku A, Sunohara N, Kinoshita M. Clinical manifestations and the diagnostic problems of multiple sclerosis in Japan. Neurology (Minneapolis) 26 (6, part 2): 23, 1976.

16) Tsubaki T, Horikawa $Y$, Iwata I, Amaya N. Clinical and immunologic studies on multiple sclerosis. Neurology (Minneapolis) $26(6$, part 2): 35, 1976.

17) Shibasaki H, Okihiro MM, Kuroiwa Y. Multiple sclerosis among Orientals and Caucasians in Hawaii: a reappraisal. Neurology 28: $113,1978$.

18) Hung T-P. Multiple sclerosis in Taiwan: A reappraisal. in: Multiple Sclerosis East and West, Kuroiwa Y, Kurland LT, Eds. Kyushu University Press, Kyushu, 1982, p.84.

19) Tan C-T. Multiple sclerosis in Malaysia. Arch Neurol 45: 624, 1988.

20) Gebarski SS, Gabrielsen TO, Gilman S, Knake JE, Latack JT, Aisen AM. The initial diagnosis of multiple sclerosis: Clinical impact of magnetic resonance imaging. Ann Neurol 17: 469, 1985.

21) Robertson WD, Li D, Mayo J, Genton M, Paty DW. Magnetic resonance imaging in the diagnosis of multiple sclerosis. J Neurol 232 (suppl): 58, 1985.

22) Lukes SA, Crooks LE, Aminoff MJ, et al. Nuclear magnetic resonance imaging in multiple sclerosis. Ann Neurol 13: 592, 1983.

23) Chippa K. Evoked Potentials in Clinical Medicine. Raven Press, New York, 1985, p.76.

24) Trojaborg W, Böttcher J, Saxtrup O. Evoked potentials and immunoglobulin abnormalities in multiple sclerosis. Neurology (NY) 31: 866, 1981.

25) Sanders EACM, Reulen JPH, Van der Velde EA, Hogenhuis LAH. The diagnosis of multiple sclerosis Combination of nonclinical tests. J Neurol Sci 72: 273, 1986.

26) Iwashita $\mathrm{H}$, Bauer $\mathrm{H}$, Kuroiwa $\mathrm{Y}$. Comparative studies of cerebrospinal fluid proteins of multiple sclerosis patients in Japan and Germany. Neurology (Minneapolis) 26 (6, part 2): 37, 1976.

27) Tabira T, Johnson KP, Vandvik B, Iwashita H. CSF immunoglobulin and virus antibody in Japanes MS: A comparative study. in: Multiple Sclerosis East and West, Kuroiwa Y, Kurland LT, Eds. Kyushu University Press, Kyushu, 1982, p.223. 